Addendum

\title{
Addendum: Li, S., et al. Risk Identification and Evaluation of the Long-term Supply of Manganese Mines in China Based on the VW-BGR Method. Sustainability 2019, 11, 2683
}

\author{
Shule Li ${ }^{1,2,3}$, Jingjing Yan ${ }^{1,2,3, *}$, Qiuming Pei ${ }^{4, *}{ }^{-}$, Jinghua Sha ${ }^{1,2,3}$, Siyu Mou ${ }^{1,2,3}$ and \\ Yong Xiao ${ }^{4}(\mathbb{D}$ \\ 1 School of Economics and Management, China University of Geosciences, Beijing 100083, China; \\ lishule2016@163.com (S.L.); shajinghua@163.com (J.S.); mousiyu_2012@163.com (S.M.) \\ 2 Key Laboratory of Carrying Capacity Assessment for Resource and Environment, Ministry of Land and \\ Resource, Beijing 100083, China \\ 3 Lab of Resources and Environmental Management, China University of Geosciences, Beijing 100083, China \\ 4 Faculty of Geosciences and Environmental Engineering, Southwest Jiaotong University, Chengdu 611756, \\ China; xiaoyong@swjtu.edu.cn \\ * Correspondence: yanjingjing312@hotmail.com (J.Y.); pqm@swjtu.edu.cn (Q.P.)
}

Received: 9 December 2019; Accepted: 9 December 2019; Published: 11 December 2019

check for updates

The authors would like to make the following corrections about the published paper [1]. The changes are as follows:

(1) Replacing the affiliation:

School of Economics and Manganese, China University of Geosciences, Beijing 100083, China with

School of Economics and Management, China University of Geosciences, Beijing 100083, China

The authors and the Editorial Office would like to apologize for any inconvenience caused to the readers by these changes. The change does not affect the scientific results. The manuscript will be updated and the original will remain online on the article webpage.

\section{Reference}

1. Li, S.; Yan, J.; Pei, Q.; Sha, J.; Mou, S.; Xiao, Y. Risk Identification and Evaluation of the Long-term Supply of Manganese Mines in China Based on the VW-BGR Method. Sustainability 2019, 11, 2683. [CrossRef]

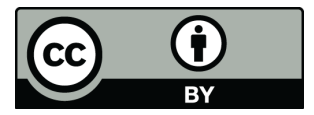

(C) 2019 by the authors. Licensee MDPI, Basel, Switzerland. This article is an open access article distributed under the terms and conditions of the Creative Commons Attribution (CC BY) license (http://creativecommons.org/licenses/by/4.0/). 